\title{
O papel da logística reversa para as empresas: fundamentos e importância
}

Mario Henrique Bueno Moreira Callefi

mariocallefi@gmail.com Universidade Estadual de Maringá (UEM), Maringá, Paraná, Brasil

\section{Willyan Prado Barbosa}

will.ec@hotmail.com

Universidade Estadual de Maringá (UEM), Maringá, Paraná, Brasil

\section{Diego Vieira Ramos}

diego.vieira.arquitetura@gmail.com

Universidade Estadual de Maringá (UEM),

Maringá, Paraná, Brasil

\author{
RESUMO
}

O cenário atual do mercado é de extrema concorrência, então para as empresas sobreviverem e ganharem novos mercados, necessitam não apenas mais fornecer produtos com preços competitivos e com qualidade, mas também adotarem estratégias que sejam fundamentadas na responsabilidade social e ambiental, melhorando assim a imagem da marca. Em relação a isso, as empresas encontraram na logística reversa, uma forma eficiente de adotarem princípios mais sustentáveis, uma vez que a logística reversa é responsável por recuperar o valor dos produtos, para que o mesmo ou seus componentes possam ser reutilizados novamente nos processos industriais, caso não seja possível a recuperação, no mínimo deve se dar um destino ambientalmente aos resíduos resultantes. Este artigo apresenta uma pesquisa sobre a influência dos conceitos que envolvem a logística reversa no âmbito ambiental e empresarial. Em relação a metodologia utilizada foi a pesquisa bibliográfica, com natureza exploratória. Para o levantamento dos dados foram utilizados dissertações, monografias, livros e artigos científicos na área da logística e logística reversa. Por meio dessa pesquisa foi possível verificar os benefícios ambientais e econômicos da adoção da logística reversa, a importância da elaboração de diretrizes públicas para a promoção da logística reversa. Além disso, constatou-se que a logística reversa é subdividida em duas áreas a logística reversa de pós-consumo e a logística de pósvenda, que se distinguem essencialmente pelo momento em que é realizado o retorno do material.
\end{abstract}

PALAVRAS-CHAVE: Logística. Logística reversa. Sistema de Logística Reversa. Logística Reversa Pós-Consumo. Logística Reversa Pós-Venda. 


\section{INTRODUÇÃO}

A logística é considerada uma das mais antigas atividades humanas, sendo usado como estratégia de operações militares e tendo como objetivo principal tornar disponível bens e serviços produzidos por uma sociedade, no tempo, nas quantidades, nos locais e na qualidade em que são exigidos (LEITE, 2009).

Segundo Ballou (1993) essencialmente a importância da logística está ligada aos custos associados às suas atividades, pois, o aumento dos custos logísticos interfere na posição das empresas no cenário de competição global e também a logística fornece suporte para sucesso nas atividades comerciais e a continuidade do modelo de desenvolvimento buscando a melhora contínua do padrão de vida nos países desenvolvidos.

No cenário atual de competição global entre empresas, não apenas as questões ligadas ao preço, prazo e qualidade são importantes, torna-se essencial também os aspectos que envolvem a logística empresarial, priorizando a busca pelo maior nível de serviço que possa ser prestado aos clientes ao menor custo possível (RAZZOLINI FILHO; BERTÉ, 2013).

Já na visão de Chaves e Batalha (2006), tradicionalmente a logística tinha como objetivo o alcance de um nível suficiente de serviços e qualidade com o menor custo possível, por meio de ações de planejamento e coordenação de atividades essenciais dentro da organização, mas atualmente está sendo percebido uma modificação desse conceito, onde além dos aspectos de qualidade e custo, está sendo exigido pelos consumidores uma preocupação também com os aspectos ambientais, sendo assim, as empresas que implantam e investem em atividades logística reversa, possui uma grande vantagem no que se refere a diferenciação do produtos e fidelização dos clientes. Porém, segundo os mesmos autores, as organizações possuem grande dificuldade de enxergar as vantagens econômicas e ambientais da logística reversa, tornando assim difícil a estruturação de canais de logística reversa eficazes.

Hernández et al. (2007) definem que as empresas por essência visam o alcance do lucro, mas no mercado atual é necessário ir além disso, tornando fundamental que as estratégias empresariais sejam fundamentadas também nos aspectos ambientais e sociais e além disso as empresas que não apenas atuam de maneira cumprir os aspectos legais definidos, mas também realizam investimentos em novas tecnologias e buscam estar alinhadas com os aspectos da responsabilidade social, tendem a melhorar sua posição em um mercado cada vez mais competitivo, onde é preciso satisfazer as necessidades de diferentes stakeholders.

Nesse contexto, enquanto na logística comum o objetivo é no planejamento de todo o processo de fluxo de mercadorias, a logística reversa propõe-se a recuperar produtos de forma sustentável e além disso a logística reversa é subdivida em duas vertentes: a logística reversa de pós consumo que se relaciona com os produtos que podem ser levados a aterros sanitários ou destinados a reciclagem, após serem consumidos e a logística reversa de pós-venda que se relaciona com os produtos após serem vendidos (CRUZ et al., 2013).

Atualmente as organizações em nível mundial estão sendo bastante exigidas pela sociedade no que tange as questões ambientais, principalmente em relação a reutilização de produtos e/ou embalagens, que consequentemente exerce grande influência para a redução dos impactos ambientais, nesse contexto é importante 
ressaltar que no Brasil a escolha das empresas por utilizarem-se ou não de embalagens retornáveis ou reutilizáveis é uma decisão meramente econômica, já que as restrições ambientais no país são poucos severas nesse sentido (BERGAMO; STEFANELLO, 2014).

De acordo com Lora (2000), anteriormente apenas as questões legais envolvendo o meio ambiente ganhavam importância, mas no cenário atual as empresas vêm percebendo que a preocupação com o meio ambiente é decisiva para a manutenção da competividade das empresarial, uma vez que o controle da geração e destinação final de resíduos possibilita que as empresas reduzam custos, minimizem impactos ambientais, atuem de forma responsável e com isso alcancem um diferencial competitivo no mercado.

Em vista disso, o presente trabalho pode ser justificado pela necessidade de se desenvolver e difundir o conhecimento técnico-científico relacionado ao tema, apresentando a importância da logística reversa para a preservação do meio ambiente e para a competividade empresarial.

O objetivo deste trabalho é realizar o levantamento bibliográfico sobre logística e logística reversa para expor a influência desses conceitos no âmbito empresarial e ambiental, destacando as vantagens da implantação de sistemas de logística reversa.

\section{METODOLOGIA}

A presente pesquisa foi elaborada por meio de dissertações, monografias, livros e artigos científicos, possuindo caráter exploratório e natureza qualitativa. Este tipo de pesquisa caracteriza-se por focar em problemas específicos através da subjetividade e objetividade, buscando constituir um maior conhecimento do problema, tornando o processo de definição de hipóteses mais simplificado (GIL, 2002; MINAYO, 2004).

Em relação aos procedimentos técnicos, essa pesquisa é classificada como bibliográfica, já que que segundo Gil (2002), este tipo de pesquisa é elaborado por meio de materiais previamente escritos, provindos prioritariamente de artigos científicos e livros, propiciando um estudo mais amplo de um número maior de problemas do que seria possível através da pesquisa direta.

O levantamento dos dados ocorreu por meio da pesquisa em diversos livros, artigos publicados em congressos e revistas, e dissertações de mestrado, envolvendo uma gama dos mais variados autores e também legislações federais. Foram priorizados livros, artigos científicos e dissertações de autores conceituados na área de logística e logística reversa.

Em seguida todo material bibliográfico levantado foi analisado e organizado, possibilitando o levantamento de conceitos e definições relacionados a pesquisa, principalmente envolvendo a logística e a logística reversa. Com isso foi possível identificar fatores e características que evidenciem a influência da logística reversa no cenário ambiental e empresarial. 


\section{LOGÍSTICA}

A logística em seus primórdios estava focada principalmente na área militar, com a preocupação restrita aos carregamentos de munições, armas e suprimentos para o campo de batalha, mas com o aumento populacional e da renda per capita, houve o crescimento das entregas de produtos em diferentes regiões, sendo preciso dessa maneira expandir a logística para outras necessidades além dos militares (GONÇALVES, 2013).

Novaes (2007) destaca que a logística pode ser entendida de acordo com definição do Council of Logistics Management norte americano, como um processo eficiente de planejamento, controle e implementação da movimentação e armazenagem de itens, serviços e informações relacionadas, abrangendo do ponto inicial até o ponto final que é o ponto de consumo, com proposito de atender as necessidades dos clientes.

Outra definição sobre conceito de logística é dada por Rosa (2011):

Logística é definida como a colocação do produto certo, na quantidade certa, no lugar certo, no prazo certo, com a qualidade certa, com a documentação certa, ao custo certo, sendo produzido ao menor custo, da melhor forma, e deslocado mais rapidamente, agregando valor ao produto e dando resultados positivos aos acionistas e aos clientes. Tudo isso respeitando a integridade humana de empregados, de fornecedores e de clientes e a preservação do meio ambiente (ROSA, 2011, P. 16).

A logística moderna tem como meta garantir a definição de prazos anteriormente acertados, que possam ser cumpridos ao longo de toda cadeia de suprimento, promover a integração correta de todos os setores da empresa e parcerias satisfatórias com fornecedores e clientes, buscar também a redução de custos logísticos e principalmente assegurar que o nível de serviço praticado esteja de acordo com os requisitos dos clientes (NOVAES, 2007).

O conceito importante na logística são as cadeias de suprimento, que Intersaberes (2014, p. 103), "contempla o fluxo total de materiais e os agentes transformadores, desde as matérias primas básicas de um processo até a entrega de todos os produtos acabados ou serviços ao consumidor, pelo ponto de venda de varejo".

A Figura 1 apresenta uma cadeia de suprimento convencional, onde temos os fornecedores de matéria prima, os fabricantes de componentes, industriais principais, atacadistas e distribuidores, varejistas e consumidores finais. 
Figura 1 - Cadeia de suprimento típica

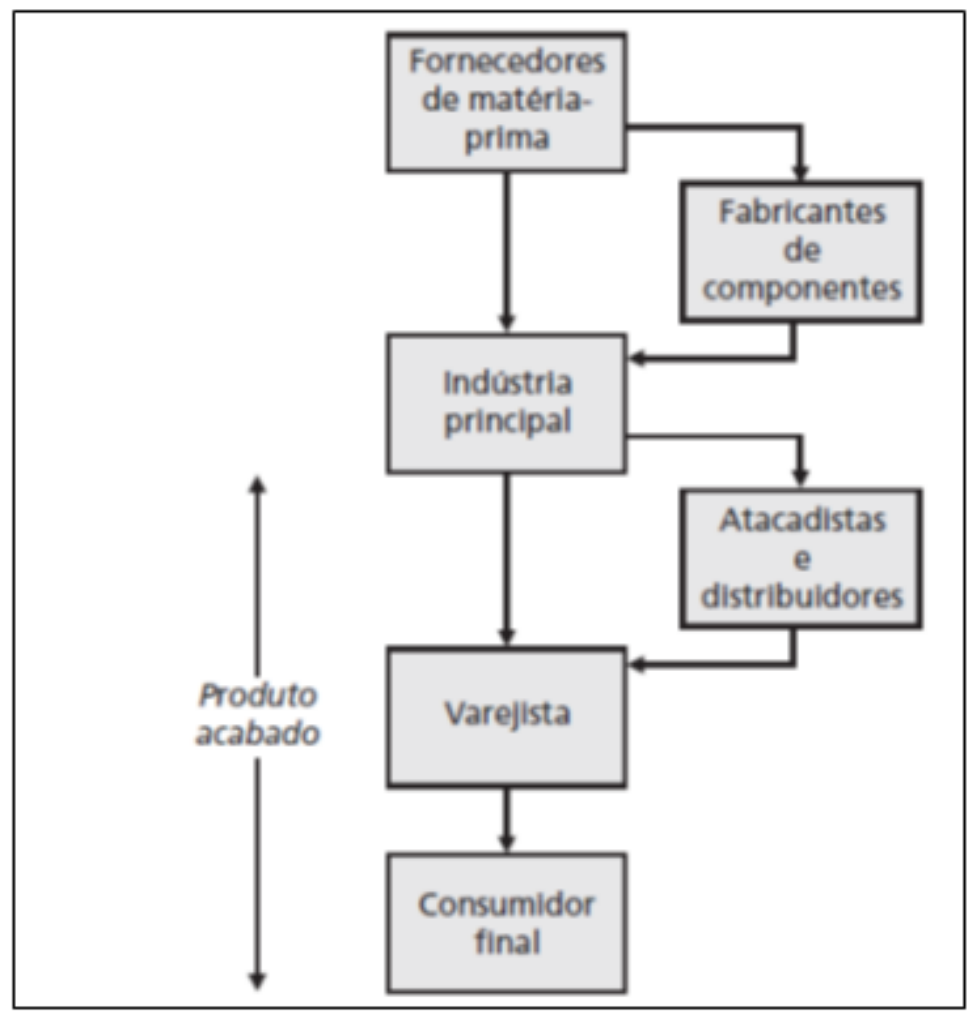

Fonte: Novaes (2007, p.39)

Segundo Taylor (2005) a maneira em que as cadeias de suprimentos são gerenciadas definem o destino das empresas, seja para prosperidade ou falência, então é necessário estabelecer um fluxo organizado em toda de cadeia de suprimentos até a chegada ao consumidor final, sendo que a atividade mais relevante a ser gerenciada é o transporte, já que ao longo de toda cadeia de suprimentos é necessário movimentar os produtos para o próximo elemento.

Um dos aspectos de maior relevância na temática da logística e ser considerado é o nível de serviço logístico, que contempla o grau de qualidade do gerenciamento do fluxo de bens de consumo e serviços, que por sua vez fornece informações importantes sobre o desempenho das atividades logísticas (INTERSABERES, 2014).

Para Suzano (2013), dentro da logística existem atividades que contribuem significativamente nos custos logísticos e interferem no sucesso das atividades logísticas, estando presentes no "ciclo crítico de atividades logísticas" (Figura 1), sendo elas:

- Transportes: responsável pelo transporte de produtos ou matérias primas, sendo considerada a atividade mais importante dentro da logística, contribuindo em até dois terços dos custos logísticos.

- Manutenção de estoques: torna-se necessário quando a entrega não pode acontecer no momento exato do fim da produção, permitem que produtos 
estejam disponível no momento da demanda, além disso, os estoques devem estar em locais próximos aos clientes ou ponto de manufatura.

- Processamento de pedidos: atividade de menor custos se comparado as demais, o baixo tempo de processamento é ideal para a cumprimento de prazos.

Figura 2 - Ciclo crítico de atividades logísticas

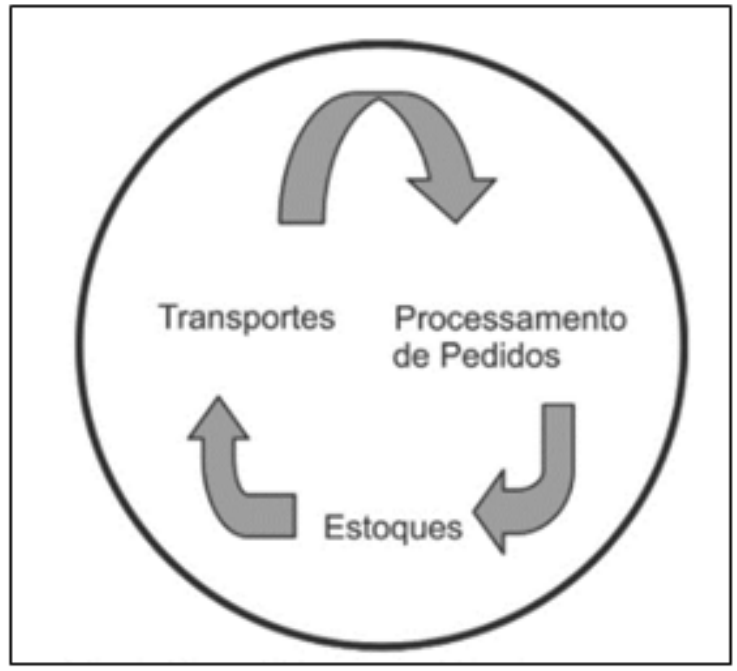

Fonte: Suzano (2013, p.191)

No cenário atual da logística moderna, torna-se essencial expandir suas ações para o meio empresarial e ambiental, nesse sentido temos a logística empresarial, a logística verde ou green logistics e a logística reversa.

\section{LOGÍSTICA EMPRESARIAL}

Buller (2012) aponta que o termo 'logística' passou por evolução no século XX, fato ligado ao crescimento de mercados consumidores, estreitamento de relação entre os países e consolidação da globalização, sendo que logística atualmente também pode ser nomeada como logística empresarial ou gestão da cadeia de suprimentos.

Entre as atividades mais importantes dentro de qualquer empresa está a logística empresarial, a envolvendo diversas áreas da organização, sendo as principais de planejamento, administração, distribuição física, organizando toda a cadeia de suprimento almejando a redução dos custos logísticos e consequentemente aumentar os lucros empresariais (CAMPOS; BRASIL, 2013).

Ballou (1993, p. 17) destaca que a logística empresarial tem por objetivo de estudo:

[..] como a administração pode prover melhor nível de rentabilidade nos serviços de distribuição aos clientes e consumidores, através de planejamento, organização e controle efetivos para as atividades de movimentação e armazenagem que visam facilitar o fluxo de produtos. 
Para o sucesso da logística empresarial é necessário existir uma cadeia suprimento integrada, para isso são desenvolvidas parcerias entre as empresas, que prioritariamente deve ser uma ligação que forneça ganhos para todos os participantes, permitindo assim que as organizações aumentem suas chances de sobreviver e de aumentar sua participação no mercado (BULLER, 2012).

\section{LOGÍSTICA VERDE}

Silva e D'Andrea (2009) definem a logística verde ou green logistics como o ramo da logística que adota os princípios da sustentabilidade ambiental para reduzir os impactos gerados pelas atividades logísticas, onde as instituições devem desenvolver ações ao longo da cadeia de valor e do ciclo de vida dos produtos vendidos, inclusive sendo responsável pelo destino final dos produtos.

As empresas no atual cenário do mercado, anseiam continuamente possuir algum diferencial competitivo em relação aos concorrentes, nesse sentido sofrem pressões constantes dos consumidores para que seja a implantado ações sustentáveis efetivas, buscando a conservação ambiental e o desenvolvimento sustentável, em decorrência desse fato as empresas utilizam dos conceitos da logística verde como forma de buscar esse alinhamento sustentável (RIBEIRO; SANTOS, 2012).

A utilização dos conceitos da logística verde são essenciais para qualquer empresa que almeje alcançar a sustentabilidade ambiental, pois permite que o gerenciamento da cadeia de suprimentos possa ser realizado de maneira em que haja o envolvimento de todos os participantes da cadeia de valor para a redução dos impactos ambientais gerador por cada atividade logística, gerando assim uma maior credibilidade da empresa junto aos consumidores, que consequentemente aumenta a possibilidade de aumento nos lucros (SILVA; D'ANDREA, 2009).

Algumas das estratégias para garantir o sucesso das ações a serem implementadas que envolvem o conceito de logística verde e sustentabilidade são: redução do consumo, reutilização de materiais, reciclagem de materiais, restruturação da cadeia logística visando a eficiência ambiental, escolha de fornecedores com base em critérios sustentáveis, educação ambiental para todos os funcionários das empresas, realização de auditorias ambientais e promover o envolvimento de todos na empresa nas ações realizadas (MURPHY; POIST, 2003).

Apesar das semelhanças entre a logística verde a logística reversa, uma vez que as duas levam em conta os aspectos ambientais das atividades logística e desenvolvem ações de reciclagem e de reutilização, apenas a logística verde envolve questões como o desenvolvimento de ações para controle e diminuição dos impactos ambientais das operações logísticas e a também de redução da geração de embalagens e da emissão de poluentes, que possibilitam por sua vez benefícios significativos para o meio ambiente (SANTOS et al., 2015).

\section{LOGÍSTICA REVERSA}

A partir da década de 1970 o grande consumo provindo da mentalidade capitalista passou a ser considerado como a principal causa dos problemas ambientais, iniciando uma mudança de pensamento por parte dos consumidores, 
passando a ser adotado uma mentalidade considerada mais sustentável de consumo. (TONETO JÚNIOR et al., 2014).

De acordo com Toneto Júnior et al. (2014) as empresas em face da mudança de mentalidade dos consumidores, perceberam a necessidade da realização de diversas ações de gestão ambiental com objetivo principal de melhorar a eficiência ambiental, nesse contexto surgiu o conceito de logística reversa ou logística inversa, visando garantir a conservação do meio ambiente, por meio do desenvolvimento de formas corretas de transporte, armazenamento e descarte dos resíduos resultantes.

A logística reversa é definida para Leite (2002) como:

[..] área da Logística Empresarial que planeja, opera e controla o fluxo, e as informações logísticas correspondentes, do retorno dos bens de pós-venda e de pós - consumo ao ciclo de negócios ou ao ciclo produtivo, através dos Canais de Distribuição Reversos, agregando-lhes valor de diversas naturezas: econômico, ecológico, legal, logístico, de imagem corporativa, entre outros. (LEITE, 2002, p. 2).

Já conforme a Política Nacional de Resíduos Sólidos (PNRS), logística reversa é definida como:

[..] instrumento de desenvolvimento econômico e social caracterizado por um conjunto de ações, procedimentos e meios destinados a viabilizar a coleta e a restituição dos resíduos sólidos ao setor empresarial, para reaproveitamento, em seu ciclo ou em outros ciclos produtivos, ou outra destinação final ambientalmente adequada. (BRASIL, 2010, art. 3).

Um conceito bastante importante para a logística reversa é o ciclo de vida dos produtos e segundo SHIBAO et al. (2010):

Por traz dessa evolução dos conceitos de logísticas reversa, está o conceito mais amplo do "ciclo de vida" do produto. Três considerações devem ser sistematicamente feitas sobre o ciclo de vida do produto:

a. Sob ponto de vista logístico: a vida de um produto não termina com sua entrega ao cliente. Produtos se tornam obsoletos, danificados, saturados em sua função ou simplesmente não funcionam e devem retornar ao seu ponto de origem para serem adequadamente descartados, reparados ou reaproveitados:

b. Sob o ponto de vista financeiro: além dos custos dos produtos até sua venda, devem ser também considerados outros custos relacionados a todo gerenciamento do fluxo reverso e

c. Sob ponto de vista ambiental: avaliar o impacto que o produto produz ao meio ambiente durante toda a sua vida. (SHIBAO et al., 2010, p. 7).

Chaves e Batalha (2006) destacam que a reciclagem é um dos processos mais essenciais para a logística reversa, no Brasil os materiais que possuem uma maior taxa de reciclagem são as embalagens de alumínio e PET (politereftalato de 
etileno), no caso das embalagens PET a taxa de reciclagem no Brasil em 2004 foi de $48 \%$, superando a taxa nos países europeus que é de apenas $31 \%$.

Além da reciclagem e da reutilização de materiais, outras atividades relativas a logística reversa são: recondicionamento e remanufatura de produtos, processamento de produtos retornados e estabelecimento de programas para reciclagem, recuperação e tratamento de resíduos perigosos (RAZZOLINI FILHO; BERTÉ, 2013).

Devido a importância dos aspectos ligados a logística reversa no Brasil, está sendo percebido que o poder público está cada vez mais buscando desenvolver legislações que definem diretrizes para garantir a redução dos impactos das atividades produtivas no meio ambiente (CHAVES; BATALHA, 2006).

Nesse contexto, foi instituído no Brasil em 2 de agosto de 2010, a Lei no 12.305, referente a PNRS que define uma obrigatoriedade para estruturação e implementação de um sistema de logística reversa, mediante retorno dos produtos após o uso pelo consumidor, para todos os fabricantes, importadores, distribuidores e comerciantes de produtos eletrônicos e seus componentes (BRASIL, 2010).

Callefi (2016) destaca que a PNRS é essencial para a correta implantação e funcionamento dos sistemas de logística reversa no Brasil, uma vez que por meio dessa lei foi intensificado as ações regulatórias do poder público sobre os fabricantes, importadores, distribuidores e comerciantes dos produtos abrangidos pela Lei no 12.305 , são eles:

I - Agrotóxicos, seus resíduos e embalagens, assim como outros produtos cuja embalagem, após o uso, constitua resíduo perigoso, observadas as regras de gerenciamento de resíduos perigosos previstas em lei ou regulamento, em normas estabelecidas pelos órgãos do Sisnama, do SNVS e do Suasa, ou em normas técnicas;

II - Pilhas e baterias;

III - Pneus;

IV - Óleos lubrificantes, seus resíduos e embalagens;

V - Lâmpadas fluorescentes, de vapor de sódio e mercúrio e de luz mista;

VI - Produtos eletroeletrônicos e seus componentes. (BRASIL, 2010, art. 33).

Epelbaum (2004) apresenta os indicadores de sucesso empresarial ligados com a implantação de ações ligadas a gestão ambiental, nesse contexto é possível considerar esses indicadores de sucesso também da implantação dos sistemas de logística reversa (Tabela 1).

Tabela 1 - Indicadores de sucesso empresarial da implantação da logística reversa

\begin{tabular}{cll}
\multicolumn{1}{c|}{ ÁREA } & \multicolumn{1}{c}{ INDICADORES DE } & \multicolumn{1}{c}{ DESCRIÇÃO DO INDICADOR } \\
\multirow{2}{*}{ Financeira } & $\begin{array}{l}\text { Indicadores } \\
\text { Financeiros } \\
\text { Convencionais }\end{array}$ & $\begin{array}{l}\text { Retorno sobre investimento, rentabilidade, } \\
\text { liquidez, retorno sobre o capital empregado }\end{array}$
\end{tabular}




\begin{tabular}{|c|c|c|}
\hline ÁREA & $\begin{array}{l}\text { INDICADORES DE } \\
\text { SUCESSO }\end{array}$ & DESCRIÇÃO DO INDICADOR \\
\hline \multirow[t]{3}{*}{$\begin{array}{l}\text { Marketing/ } \\
\text { vendas }\end{array}$} & $\begin{array}{l}\text { Participação do } \\
\text { mercado }\end{array}$ & $\begin{array}{l}\text { Valor atual líquido subtraindo-se os futuros fluxos } \\
\text { de caixa livres da empresa, descontado o valor de } \\
\text { capitais tomados de terceiros } \\
\text { É um tradicional indicador de sucesso empresarial, } \\
\text { particularmente para empresas com estratégias de } \\
\text { crescimento e/ou em setores novos da economia. } \\
\text { É muito utilizada na definição de estratégias de } \\
\text { marketing, utilizando-se ferramentas como a } \\
\text { matriz de portfólio de produto (conhecida como } \\
\text { matriz BCG, em função do nome da instituição de } \\
\text { origem). }\end{array}$ \\
\hline & $\begin{array}{l}\text { Atração e retenção de } \\
\text { clientes }\end{array}$ & $\begin{array}{l}\text { Tradicional indicador do sucesso empresarial, } \\
\text { mensurado por pesquisas ou por estatísticas de } \\
\text { compras. }\end{array}$ \\
\hline & $\begin{array}{l}\text { Valor da marca e } \\
\text { reputação }\end{array}$ & $\begin{array}{l}\text { Definem imagem como uma composição das } \\
\text { atitudes e crenças das pessoas sobre uma } \\
\text { organização }\end{array}$ \\
\hline Operações & Eficiência operacional & $\begin{array}{l}\text { Habilidade de uma companhia em transformar } \\
\text { insumos em produtos/serviços com boa relação } \\
\text { custo-benefício. }\end{array}$ \\
\hline $\begin{array}{l}\text { Desenvolvi } \\
\text { mento }\end{array}$ & Inovação & $\begin{array}{l}\text { Processo de transformar oportunidades em novas } \\
\text { ideias, e colocá-las em amplo uso prático }\end{array}$ \\
\hline $\begin{array}{l}\text { Recursos } \\
\text { Humanos }\end{array}$ & $\begin{array}{l}\text { Capital intelectual e } \\
\text { humano }\end{array}$ & $\begin{array}{l}\text { Capacidade que um indivíduo tem para agir em } \\
\text { diversas situações e criar tanto ativo tangíveis } \\
\text { como intangíveis. }\end{array}$ \\
\hline
\end{tabular}

Fonte: Adaptado de Epelbaum (2004).

Além disso, a implantação de sistemas de logística reversa é de extrema importância para qualquer empresa, trazendo diversos benefícios ambientais (Figura 3) e econômicos (Figura 4).

Figura 3 - Benefícios ambientais da implantação de sistemas de logística reversa

BENEFÍCIOS AMBIENTAIS

- Redução do volume de descarte tanto seguras quanto ilegais;

- Antecipação às exigências de regulamentações legais;

- Economia de energia na fabricação de novos produtos;

- Diminuição da poluição pela contenção dos resíduos;

- Restrição dos riscos advindos de aterros;

- Melhoria da imagem corporativa;

- Consciência ecológica.

Fonte: CRUZ et al. (2013, p.3) 
Figura 4 - Benefícios econômicos da implantação de sistemas de logística reversa

\begin{tabular}{|l|}
\hline \multicolumn{3}{|c|}{ BENEFÍCIOS ECONÔMICOS } \\
\hline - Criação de novos negócios na cadeia \\
produtiva; \\
- Redução de investimentos em fábricas; \\
- Economia do custo de energia na fabricação; \\
- Aumento de fluxo de caixa por meio da \\
comercialização dos produtos secundários e \\
dos resíduos; \\
- Aproveitamento do canal de distribuição para \\
escoar os produtos secundários nos mercados \\
Secundários; \\
Melhoria da imagem corporativa para obter \\
financiamentos subsidiados por operar com \\
práticas ecologicamente corretas.
\end{tabular}

Fonte: CRUZ et al. (2013, p.3)

Rodrigues et al. (2002) aponta que logística reversa está ainda pouco estabelecida no Brasil, mas diversas empresas já desenvolvem atividades na área, sendo percebidos alguns aspectos importantes que serão crucias para o crescimento da logística reversa no país, são eles: necessidade da identificação de possíveis intermediários no fluxo reversos e definição do grau de importância de cada um, desenvolvimento de parcerias que sejam consideradas mais profissionais, sendo possível melhorar o grau de eficiência das atividades realizadas, realização de ações de planejamento para aprimorar a eficiência da cadeia reversa e implantação de sistemas de gerenciamento ambiental como a ISO 14001.

Leite (2002) subdivide a logística reversa em duas áreas de atuação, o pósconsumo e o pós-venda, onde as mesmas podem ser distinguidas de acordo com o estágio do ciclo de vida em que determinado produto retornou. A Figura 5 apresenta as áreas da logística reversa e as etapas que envolve a mesma.

Figura 5 - Áreas de atuação da logística reversa e etapas reversas

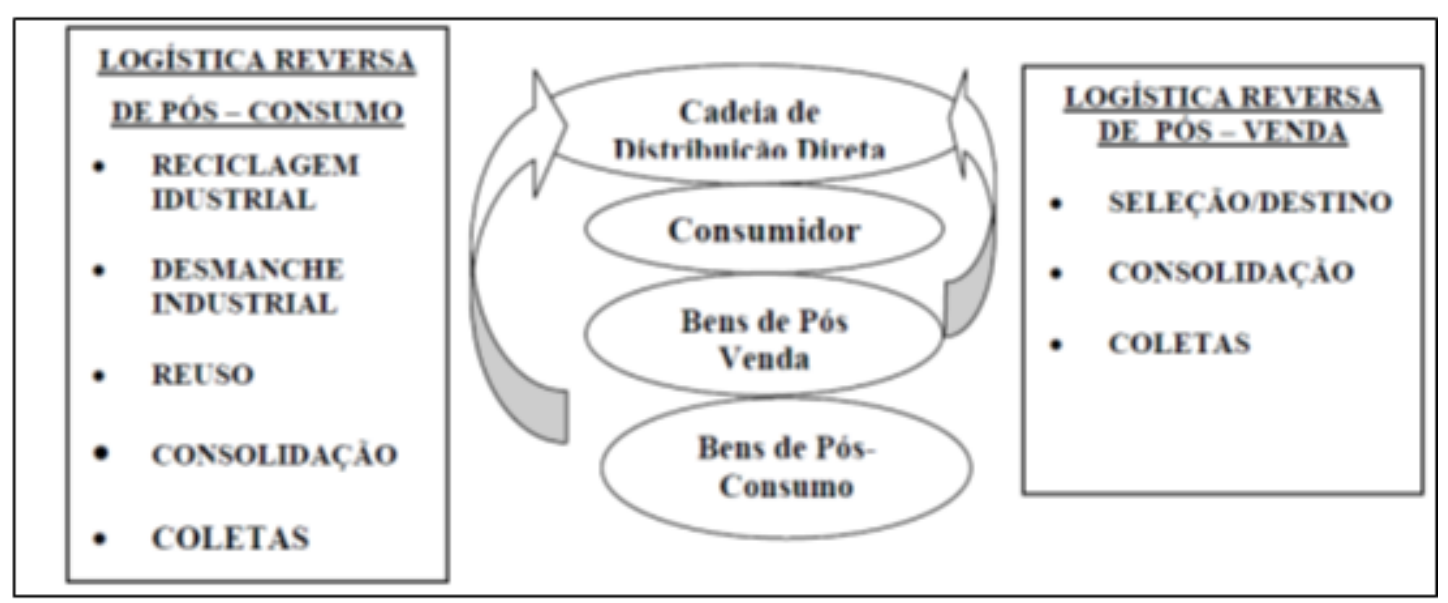


A logística reversa de pós-venda pode ser diferenciada da logística de pósconsumo, por envolver o retorno de produtos provindos de elos da cadeia de distribuição logística ou mesmo pelo consumidor final, que tiveram pouca ou nenhuma utilização, enquanto o pós-consumo envolve produtos que já foram consumidos e podem ser reciclados, reaproveitados ou no mínimo ter um destino ambientalmente correto (LEITE, 2009).

Rodrigues et al. (2002) a logística reversa de pós-consumo é caracterizada pelo reaproveitamento e reciclagem de materiais e componentes após o consumo, sendo realizado em diversos casos incentivo para os consumidores trocarem seus antigos produtos por novos, obtendo descontos nessa troca, demostrando assim a capacidade das empresas de adotar uma postura ambientalmente correta, consequentemente melhorando sua posição junto aos clientes. De acordo com o mesmo autor, já logística reversa de pós-venda pode ser caracterizada pelo retorno dos produtos por motivos de devolução ou mesmo recall, sendo esse retorno devido a diversas causas, final do prazo de validade dos produtos, obsolescência devido a sazonalidade ou lançamentos de novos modelos.

\section{CONSIDERAÇÕES FINAIS}

A partir dos artigos, livros e trabalhos acadêmicos selecionados foi possível identificar a importância e vantagens da implantação de sistemas de logística reversa no âmbito empresarial e ambiental.

A logística reversa difere-se da logística tradicional em relação aos objetivos, enquanto a logística reversa tem foco de recuperar, reciclar ou pelo dar um destino ambiente correto para os produtos, existindo uma preocupação com o retorno dos produtos depois do ponto final de consumo, a logística convencional tem como foco a cadeia logística do ponto inicial até o ponto de consumo, não havendo qualquer planejamento do retorno dos produtos.

Para o cenário empresarial a logística reversa apresenta diversas vantagens para sua adoção, diminuição do consumo de energia, possibilidade de aumento dos lucros com a criação de novos negócios na cadeia produtiva, aumento da capacidade de obtenção de financiamentos para investimentos e o ponto principal para a implantação de sistemas de logística reversa está na atração de novos clientes e fidelização dos existentes, já que os consumidores tem a tendência de optarem por empresas que adotem práticas sustentáveis.

As vantagens da logística reversa para o meio ambiente, encontra-se na adoção de práticas para redução da quantidade de resíduos descartados, redução do consumo de energia e matérias primas, diminuição da geração de agentes poluidores, disseminação dos conceitos da responsabilidade ambiental, entre outros.

A importância da reciclagem para a logística reversa é fato a ser destacado, onde o país apresenta números superiores aos dos países europeus em relação a reciclagem de embalagens de alumínio e PET. Para que números como estes tornem cada vez mais expressivos, é necessário o envolvimento do setor público para a elaboração de novas legislações que possam propor ações para a redução dos impactos ambientais das atividades produtivas. 
Nesse contexto, torna-se claro que no Brasil a logística reversa tem ganhado cada vez mais importância, mas a partir da aprovação da PNRS em 2010 que a logística reversa avançou ainda mais, pois a mesma estabeleceu a obrigatoriedade da implantação de sistemas de logística reversa para diversos produtos, envolvendo toda a cadeia de valor.

Outro fato importante no presente trabalho foi a apresentação dos conceitos de logística verde, que se diferencia da logística reversa por alguns aspectos citados no Item 3.1.2, mas o mesmo também abrange conceitos ligados ao desenvolvimento sustentável e preservação do meio ambiente, então entre as recomendações para estudos futuros estão: comparação aprofundada dos conceitos da logística reversa e logística verde, importância da logística verde para o cenário ambiental e empresarial. Já em relação a logística reversa, inúmeros estudos podem ser feitos a partir desse trabalho, entre eles: desenvolvimento de um estudo de caso abrangendo os conceitos apresentados e realização de um aprofundamento nas questões dos custos da logística reversa, sendo possível identificar possíveis vantagens e desvantagens financeiras da adoção da logística reversa. 


\title{
The role of reverse logistics for business: fundamentals and importance
}

\begin{abstract}
The current market scenario is extreme competition, so that companies survive and gain new markets, not only need to provide competitively priced and quality products, but also adopt strategies that are based on social and environmental responsibility, thus improving the image of brand. In this regard, companies found in reverse logistics an efficient way to adopt more sustainable principles, since reverse logistics is responsible for recovering the value of products, so that the same or its components can be reused again in industrial processes, if recovery is not possible, at least the resulting waste must be disposed of in an environmentally sound manner. This article presents a research on the influence of the concepts that involve the reverse logistics in the environmental and business scope. In relation to the methodology used was the bibliographic research, with an exploratory nature. For the data collection, dissertations, monographs, books and scientific articles were used in the area of logistics and reverse logistics. Through this research, it was possible to verify the environmental and economic benefits of the adoption of reverse logistics, the importance of the elaboration of public guidelines for the promotion of reverse logistics. In addition, it was found that reverse logistics is subdivided into two areas: post-consumer reverse logistics and post-sale logistics, which are distinguished essentially by the moment the material is returned.
\end{abstract}

KEYWORDS: Logistics. Reverse Logistic. Reverse Logistics System. Post-Consumer Reverse Logistics. Reverse Logistics After Sales. 
BALLOU, R. H. Logística Empresarial: transportes, administração de materiais, distribuição física. São Paulo: Atlas, 1993.

BERGAMO, K. M. L.; STEFANELLO, P. R. Logística reversa nos ambientes empresariais. Revista Meio Ambiente e Sustentabilidade, v. 5, n. 3, jan/jun 2014.

BRASIL. Lei Federal 12.305, de 02 de agosto de 2010. Institui a Política Nacional de Resíduos Sólidos. Diário Oficial [da] República Federativa do Brasil, Poder Executivo, Brasília, DF, 2010.

BULLER, L. S. Logística empresarial. Curitiba: IESDE Brasil, 2012.

CALLEFI, M. H. B. M.; BARBOSA, W. P. GERÔNIMO, B. M. Gestão de resíduos de equipamentos elétricos e eletrônicos - estudo de caso em uma cooperativa de reciclagem no município de Maringá/PR. In: SIMPÓSIO DE ENGENHARIA DE PRODUÇÃO - SIMEPRO, 2016, Maringá. Anais... Maringá, 2016.

CAMPOS, L. F. R.; BRASIL, C. V. M. Logística: teia de relações. Curitiba: InterSaberes, 2013.

CHAVES, G. L. D.; BATALHA, M. O. Os consumidores valorizam a coleta de embalagens recicláveis? Um estudo de caso da logística reversa em uma rede de hipermercados. Revista Gestão \& Produção, v. 13, n. 3, set/dez 2006.

CRUZ, C. A. B.; SANTANA, R. S.; SANDES, I. S. F. A logística reversa como diferencial competitivo nas organizações. Revista Científica do ITPAC, v. 6, n. 4, out 2013.

EPELBAUM, M. A influência da gestão ambiental na competitividade e no sucesso empresarial. 2004. 190 f. Dissertação (Mestrado Engenharia de Produção) - Escola Politécnica, Universidade de São Paulo, São Paulo. crossref

GIL, A. C. Como elaborar projetos de pesquisa. 4 ed. São Paulo: Atlas, 2002.

GONÇALVES, P. S. Logística e cadeia de suprimentos: o essencial. Barueri: Manole, 2013.

HERNÁNDEZ, C. T.; KELLY, L. H. F.; MARINS, F. A. S.; CASTRO, R. C. A logística reversa e a responsabilidade social corporativa: um estudo de caso num consórcio de gestão de resíduos. In: SIMPÓSIO DE EXCELÊNCIA EM GESTÃO E TECNOLOGIA - SEGeT, 4, 2007, Resende. Anais... Resende, 2007.

INTERSABERES (Org.). Gestão em logística. Curitiba: InterSaberes, 2014.

LEITE, P. R. Logística Reversa: meio ambiente e competitividade. 2 ed. São Paulo: Prentice Hall, 2009.

LEITE, P. R. Logística reversa: nova área da logística empresarial. Tecnologística, ed. 78, p. 122-131, 2002. 
LORA, E. Prevenção e controle da poluição no setor energético industrial e transporte. Brasília: ANEEL, 2000.

MINAYO, M. C. S. Pesquisa Social: teoria, método e criatividade. 23 ed. Petrópolis: Vozes. 2004.

MURPHY, P. R. POIST, R. F. Green perspectives and practices: a "comparative logistics" study. Supply Chain Management: An International Journal, v. 8, n. 2, p. 122-131, 2003. crossref

NOVAES, A. G. Logística e gerenciamento da cadeia de distribuição. Rio de Janeiro: Elsevier, 2007

RAZZOLINI FILHO, E; BERTÉ, R. O reverso da logística e as questões ambientais no Brasil. Curitiba: InterSaberes, 2013.

RIBEIRO, R. B.; SANTOS, E. L. Análise das Práticas Estratégicas da Logística Verde no Gerenciamento da Cadeia de Suprimentos. Revista de Administração da UNIFATEA, v. 5, n. 5, set/dez 2012.

RODRIGUES, D. F.; RODRIGUES, G. G.; LEAL, J. E.; PIZZOLATO, N. D. Logística reversa - conceitos e componentes do sistema. In: XXII ENCONTRO NACIONAL DE ENGENHARIA DE PRODUÇÃO - ENEGEP, 22, 2010, Curitiba. Anais... Curitiba, 2002.

ROSA, R. A. Gestão de operações e logística I. Florianópolis: UFSC, 2011.

SANTOS, J. S.; BORTOLON, K. M.; CHIROLI, D. M. G.; OIKO, O. T. Logística verde: conceituação e direcionamentos para aplicação. Revista Eletrônica em Gestão, Educação e Tecnologia Ambiental Santa Maria, v. 19, n. 2, p. 314-331, mai/ago. 2015.

SHIBAO, F. Y.; MOORI, R. G.; SANTOS, M. R. A logística reversa e a sustentabilidade empresarial. In: XIII SEMINÁRIOS EM ADMINISTRAÇÃO SemeAd, 13, 2010, São Paulo. Anais... São Paulo, 2010.

SILVA, R. P. B.; D'ANDREA, T. Q. G. Logística reversa e logística verde: do conceito a prática. 2009. 166 f. Monografia (Graduação em Administração) Universitário Católico Salesiano Auxilium - UNISALESIANO, Lins.

SUZANO, M. A. Administração da produção e operações com ênfase em logística. Rio de Janeiro: Interciência, 2013.

TAYLOR, D. A. Logística na cadeia de suprimentos: uma perspectiva gerencial. São Paulo: Pearson Addison-Wesley, 2005.

TONETO JÚNIOR, R.; SAIANI, C. C. S.; DOURADO, J. (Org.). Resíduos sólidos no Brasil: oportunidades e desafios da lei federal $n$ ㅇ 12.305. Barueri: Minha Editora, 2014. 
Recebido: 28 abr. 2017

Aprovado: $18 \mathrm{dez} .2017$

DOI: $10.3895 /$ gi.v13n4.5844

Como citar:

CALLEFI, M. H. B. M.; BARBOSA, W. P.; RAMOS, D. V. O papel da logística reversa para as empresas: fundamentos e importância. R. Gest. Industr., Ponta Grossa, v. 13, n. 4, p. 171-187, out./dez. 2017.

Disponível em: <https://periodicos.utfpr.edu.br/rgi>. Acesso em: XXX.

Correspondência:

Mario Henrique Bueno Moreira Callefi

Av. Colombo, 5790 Jd. Universitário, Maringá, Paraná, Brasi

Direito autoral: Este artigo está licenciado sob os termos da Licença Creative Commons-Atribuição 4.0 Internacional.

(c) (1) 